\title{
Dietary supplementation
} with shiikuwasha extract attenuates dexamethasone-induced skeletal muscle atrophy in aged rats

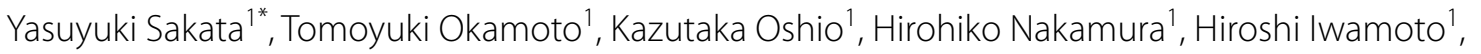 \\ Kazuyoshi Namba', Yasuhiro Takeda' and Fumiaki Yoshizawa²
}

\begin{abstract}
Background: Skeletal muscle atrophy is caused by a variety of diseases and conditions. In particular, skeletal muscle atrophy in the elderly contributes to a loss of independence with advanced age and increases the risk of falling. However, the effect of food consumed on a daily basis on skeletal muscle atrophy has been the focus of little research. In this study, the effects of dietary supplementation with shiikuwasha extract or grape extract on dexamethasoneinduced skeletal muscle atrophy were evaluated in aged rats.

Methods: Aged male rats (15-month-old) were fed a diet supplemented with either $1 \%$ shiikuwasha extract or $1 \%$ grape extract for 19 days. During the last 5 days of the feeding period, rats were injected with dexamethasone to induce muscle atrophy.

Results: Body weight and hind-limb muscle weight were significantly decreased by dexamethasone treatment. The supplementation of shiikuwasha extract showed no effect on body weight loss, but markedly attenuated tibialis anterior muscle weight loss induced by dexamethasone. On the other hand, grape extract did not affect muscle weight loss. Furthermore, shiikuwasha extract significantly reduced dexamethasone-induced expression of atrogin-1 and MURF1 mRNA, but did not reduce LC3B-II protein levels.
\end{abstract}

Conclusion: These results suggest that shiikuwasha extract may partially inhibit the activation of the ubiquitin-proteasome system and may consequently attenuate skeletal muscle atrophy induced by dexamethasone in aged rats.

Keywords: Rat, Skeletal muscle atrophy, Glucocorticoid, Shiikuwasha, Polymethoxylated flavones

\section{Background}

Skeletal muscle atrophy is caused by a variety of diseases and conditions including malnutrition, disuse, sepsis, cachexia, and glucocorticoid excess. In particular, skeletal muscle atrophy in the elderly contributes to a loss of independence with advanced age and increases the risk of falling (Landi et al. 2012); therefore, skeletal muscle

\footnotetext{
*Correspondence: ys-sakata@morinagamilk.co.jp

${ }^{1}$ Nutrition Research Department, Nutritional Science Institute, Morinaga Milk Industry Co., Ltd., 1-83, 5-Chome, Higashihara, Zama, Kanagawa 252-8583, Japan

Full list of author information is available at the end of the article
}

atrophy is a very important problem in an aging society. Many pathological conditions that cause muscle atrophy, such as sepsis, cachexia and starvation, are associated with increases in circulating glucocorticoid levels (Schakman et al. 2008). Moreover, sepsis-induced muscle atrophy is attenuated by treatment with a glucocorticoid receptor antagonist (Fischer et al. 2000). These results suggest that glucocorticoids are partly responsible for muscle atrophy under these conditions. In addition, muscle atrophy induced by disuse is exacerbated by hypercortisolemia (Fitts et al. 2007); therefore, it is thought that many factors are involved in the progression of muscle atrophy. 
Glucocorticoids such as dexamethasone induce body weight loss, skeletal muscle atrophy, and acute insulin resistance (Pagano et al. 1983; Ruzzin et al. 2005). In skeletal muscle, glucocorticoids induce selective loss of fast-twitch type- 2 muscle fibers, and might not affect type-1 muscle fibers (Dekhuijzen et al. 1995). Ubiquitinproteasome system and autophagy- lysosomal system play significant role in the protein degradation of muscle (Sandri 2013). It has been reported that both pathways are also activated during skeletal muscle atrophy induced by glucocorticoids, showing increased mRNA expression of muscle-specific ubiquitin E3 ligases, atrogin-1 and MuRF1 (Auclair et al. 1997), and the lipidated form of LC3 (LC3-II) protein, which is known as marker of autophagy (Penna et al. 2013). Glucocorticoids also affect muscle protein synthesis. Glucocorticoids reduce mRNA expression of IGF-1, which promotes protein synthesis (Gayan-Ramirez et al. 1999), and phosphorylated ribosomal protein S6 kinase 1 (S6K1), which is one of the regulators involved in the initiation of mRNA translation, in type-2 fiber rich muscles (Shimizu et al. 2011). The responsiveness of muscle protein metabolism to glucocorticoids is known to be affected by age. Muscle protein synthesis stimulated by insulin or IGF-1 is inhibited by glucocorticoids more strongly in aged rats than in young rats (Dardevet et al. 1998). In addition, glucocorticoid excess was observed to induce a prolonged leucine resistance in muscle protein synthesis in aged rats (Rieu et al. 2004). These results indicate that aging increases the sensitivity to glucocorticoid-induced muscle atrophy.

Polyphenols, widely contained in fruits, have been reported to have various physiological effects. Shiikuwasha (Citrus depressa Hayata) fruit contains many polyphenols, such as polymethoxylated flavones (Nogata et al. 2006). Nobiletin (5,6,7,8,3', $4^{\prime}$-hexamethoxy flavone), a polymethoxylated flavone from citrus, and its demethylated metabolites have been reported to have many beneficial effects, such as reduced oxidative stress ( $\mathrm{Lu}$ et al. 2010), improved insulin sensitivity (Lee et al. 2010) and anti-inflammation (Lai et al. 2008). Grapes (Vitis vinifera) are also known to contain many polyphenols, including the stilbenoid resveratrol (Siemann and Creasy 1992). Resveratrol has been reported to have many functions, including SIRT1 activation (Howitz et al. 2003), antioxidant (Jackson et al. 2011) and anti-inflammation (Subbaramaiah et al. 1998) activities.

Interestingly, it has been reported that some polyphenols such as resveratrol and 8-prenylnaringenin are effective in preventing muscle atrophy caused by disuse or aging (Momken et al. 2011; Mukai et al. 2012). Moreover, resveratrol is reported to prevent dexamethasoneinduced increases in protein degradation in cultured myotubes (Alamdari et al. 2012). However, the inhibitory effects of polyphenols on glucocorticoid-induced muscle atrophy in vivo have not been fully elucidated. The aim of this study was to examine whether extracts of these polyphenol-rich fruits have a protective effect on dexamethasone-induced muscle atrophy in aged rats.

\section{Methods}

\section{Shiikuwasha and grape extracts}

The shiikuwasha and grape extracts were obtained from ARKRAY, Inc. Karada Lab (Kyoto, Japan) and Oryza Oil \& Fat Chemical (Aichi, Japan), respectively. Shiikuwasha extract contains cyclodextrin in order to increase its solubility in water. The polyphenols contained in these extracts are presented in Table 1.

\section{Animals and treatment}

Fifteen-month-old Sprague-Dawley rats were purchased from Charles River Japan (Yokohama, Japan). They were housed under controlled temperature $\left(21-25^{\circ} \mathrm{C}\right)$, humidity (40-60\%), and lighting (on at 8 a.m. and off at 8 p.m.). All animal studies were approved by the Animal Research Committee of Morinaga Milk Industry. Following 1 week of acclimatization, the rats were divided into 4 groups: control (CTL group; $\mathrm{n}=6$ ), dexamethasone (DEX group; $n=6$ ), dexamethasone plus shiikuwasha extract $(\mathrm{DEX}+\mathrm{SE}$ group; $\mathrm{n}=5)$, and dexamethasone plus grape extract (DEX + GE group; $n=6$ ). Shiikuwasha or grape extract was added to the standard AIN-93M rodent diet at $1 \%$ by weight. Rats in the DEX + SE and DEX + GE groups were fed the diet supplemented with shiikuwasha or grape extract, respectively. CTL and DEX groups were fed AIN-93M purified rodent diet. Rats were fed each experimental diet for 19 days. To control for variations in dietary intake in the initial few days, after 1-week acclimatization to the experimental diets, dietary intake was recorded for the following 12 days. During the last 5 days of feeding, the DEX, DEX + SE and DEX + GE

Table 1 Composition of shiikuwasha (Citrus depressa Hayata) and grape (Vitis vinifera) extracts

\begin{tabular}{lll}
\hline Extract & Component & Proportion (\%) \\
\hline Shiikuwasha extract & $\begin{array}{c}\text { Cyclodextrin } \\
\text { Nobiletin }\left(5,6,7,8,3^{\prime}, 4^{\prime} \text {-hexam- }\right. \\
\text { ethoxyflavone) }\end{array}$ & 50.0 \\
& $\begin{array}{l}\text { Tangeretin }\left(5,6,7,8,4^{\prime} \text {-pen- }\right. \\
\text { tamethoxyflavone) }\end{array}$ & 4.1 \\
& Other polyphenols & About 11.0 \\
& Other ingredients & About 26.0 \\
Grape extract & Resveratrol & 5.0 \\
& Other polyphenols & About 35.0 \\
& Other ingredients & About 60.0 \\
\hline
\end{tabular}


groups were injected with dexamethasone $(750 \mu \mathrm{g} / \mathrm{kg}$ B.W.; Fujita Medical, Tokyo, Japan) intraperitoneally once per day between 10 and $11 \mathrm{a} . \mathrm{m}$. The dose and treatment period of dexamethasone are based on the methods of Minet-Quinard et al. (2000). The CTL group was injected with an equal volume of saline. Rats in all groups, except the CTL group, were provided diet and water ad libitum. The CTL group was pair-fed with the DEX group during dexamethasone treatment. A day after the last dexamethasone treatment, the rats were anesthetized with sevoflurane and sacrificed. Immediately after, blood was taken and the hind limb muscles [gastrocnemius, soleus, tibialis anterior (TA), and extensor digitorum longus (EDL)] were excised. Blood samples were centrifuged at $1000 \mathrm{~g}$ for $15 \mathrm{~min}$, and sera were collected and stored at $-80^{\circ} \mathrm{C}$ until used in assays. The TA muscle was divided into two parts; one part of the TA and the EDL were frozen in liquid nitrogen, and the other part was stored in RNAlater (Applied Biosystems, Foster City, CA) at $4{ }^{\circ} \mathrm{C}$ overnight and then stored at $-80{ }^{\circ} \mathrm{C}$ until analysis. Gastrocnemius muscles were excised, immediately weighed, and homogenized with 7 volumes of homogenization buffer (20 mM N-2-hydroxyethylpiperazine- $N^{\prime}$-2-ethanesulforic acid at $\mathrm{pH} 7.4,100 \mathrm{mM} \mathrm{KCl}, 0.2 \mathrm{mM}$ EDTA, $2 \mathrm{mM}$ ethylene glycol-bis ( $\beta$-aminoethylether)- $N, N, N^{\prime}, N^{\prime}$,-tetraacetic acid, $1 \mathrm{mM}$ dithiothreitol, $50 \mathrm{mM}$ sodium fluoride, $50 \mathrm{mM} \beta$-glycerophosphate, $0.1 \mathrm{mM}$ phenylmethyl sulfonyl fluoride, $1 \mathrm{mM}$ benzamidine, and $0.5 \mathrm{mM}$ sodium vanadate) using a Polytron homogenizer (Kinematica, Littau, Switzerland).

\section{Immunoblotting}

The gastrocnemius muscle homogenate was centrifuged at $10,000 \mathrm{~g}$ for $10 \mathrm{~min}$ at $4{ }^{\circ} \mathrm{C}$. The supernatant was mixed with an equal volume of $2 \times$ SDS sample buffer, and the diluted gastrocnemius muscle sample was subjected to electrophoresis on a $7.5 \%$ polyacrylamide gel for S6K1 analysis or a 4-15\% gradient gel (Bio-Rad, Hercules, CA) for LC3B and GAPDH analyses. The samples were subjected to protein immunoblot analysis using S6K1 polyclonal antibodies (dilution 1:500, sc-230, Santa Cruz Biotechnology, Santa Cruz, CA), LC3B antibody (\#2775, Cell Signaling Technology, Danvers, MA) or GAPDH antibody (\#2775, Cell Signaling Technology). The S6K1 phosphorylation ratio was quantified using the ratio of the heavier phosphorylated forms $(\beta+\gamma$ forms) to total immune reactivity $(\alpha+\beta+\gamma$ forms), because S6K1 resolves into multiple electrophoretic forms as a result of reduced electrophoretic mobility with increased phosphorylation, as described previously (Kimball et al. 1998, Yoshizawa et al. 2001). The protein content was normalized to GAPDH in the LC3B analysis.

\section{Protein content and TBARS}

Protein concentrations of TA muscles were measured using the DC protein assay (Bio-Rad). The total protein content of each muscle was then calculated by multiplying protein concentration, homogenate volume, and the fraction of the ground portion relative to total muscle wet weight. TBARS was measured in whole EDL muscle homogenate by using the modified methods of Ohkawa et al. (1979).

\section{Serum insulin}

Serum insulin concentrations were measured using a commercial ELISA kit (Morinaga Institute of Biological Science, Kanagawa, Japan).

\section{mRNA levels}

Total mRNA of TA muscles was extracted with TRIzol reagent (Invitrogen, Carlsbad, CA) according to the manufacturer's instructions. The isolated RNA was purified with an RNeasy mini kit (Qiagen, Dusseldorf, Germany), and its quality was analyzed using the Experion system (Bio-Rad). Total RNA was reverse-transcribed to cDNA using Taqman reverse transcription reagents (Applied Biosystems). Real-time PCR was performed with an ABI PRISM 7500 fast real-time PCR system (Applied Biosystems). The PCR primers and probes for atrogin-1 (Rn00591730), MuRF1 (Rn00590197), IGF-1 (Rn00710306) and GAPDH (Rn01775763) were purchased from Applied Biosystems. The target gene expression was normalized to the expression of the control gene GAPDH.

\section{Statistical analysis}

All values are presented as mean \pm SEM. JMP software (SAS Institute Inc., Cary, NC) was used for all statistical analyses. Results showing significant differences between the CTL and DEX groups, according to the Student's $t$ test, were analyzed with Dunnett's test for multiple comparisons between the extract supplemented groups and the DEX group. Values of $P<0.05$ were considered to be statistically significant.

\section{Results \\ Body weight, dietary intake, and serum insulin}

Body weights before dexamethasone treatment were not different among the groups (Table 2). During the dexamethasone treatment period, dietary intake in the DEX group was not different from that in the CTL group; however, body weight in the DEX group was significantly lower than in the CTL group. Body weight loss in both extract-supplemented groups (DEX + SE and $\mathrm{DEX}+\mathrm{GE}$ ) was not significantly different from that in the DEX group. Hyperinsulinemia was observed in the 
Table 2 Effects of shiikuwasha or grape extract supplementation on dexamethasone-induced changes

\begin{tabular}{llccc}
\hline & CTL & DEX & DEX + SE & DEX + GE \\
\hline Body weight (g) & & & & \\
$\quad$ Before DEX treatment & $766.5 \pm 32.8$ & $757.6 \pm 25.1$ & $757.2 \pm 20.5$ & $777.0 \pm 46.1$ \\
$\quad$ After DEX treatment & $735.0 \pm 31.9$ & $638.5 \pm 20.1^{*}$ & $654.5 \pm 19.8$ & $663.5 \pm 37.6$ \\
Body weight loss (g) & $31.57 \pm 2.84$ & $119.06 \pm 8.68^{*}$ & $102.74 \pm 10.66$ & $113.58 \pm 10.68$ \\
Average dietary intake (g) & & & & \\
$\quad 7$ days before DEX treatment & $22.4 \pm 0.30$ & $21.6 \pm 0.72$ & $19.4 \pm 1.01$ & $20.94 \pm 0.51$ \\
5 days during DEX treatment & $13.1 \pm 0.14$ & $11.52 \pm 0.91$ & $9.33 \pm 0.86$ & $11.14 \pm 1.12$ \\
Serum insulin (ng/ml) & $0.56 \pm 0.13$ & $12.03 \pm 2.54^{*}$ & $8.42 \pm 1.42$ & $14.06 \pm 2.98$ \\
\hline
\end{tabular}

Values are mean \pm SEM $(n=5$ or 6$)$

$C T L$ control group, $D E X$ dexamethasone treatment group, $D E X+S E$ dexamethasone treatment and shiikuwasha extract supplemented group, $D E X+G E$ dexamethasone treatment and grape extract supplemented group

* $P<0.05$ CTL versus DEX (student t-test)

dexamethasone treated groups. A significant difference in serum insulin levels was not observed between either of the extract supplemented groups and the DEX group (Table 2).

\section{Skeletal muscle weight}

The weights of the gastrocnemius, TA and EDL muscles were significantly reduced in the DEX group compared to the CTL group, while the weight of the soleus muscle was not changed (Fig. 1). TA muscle weight in the DEX + SE group was markedly higher than in the DEX group (Fig. 1b). Similarly, the EDL muscle weight tended to be increased in the DEX + SE group compared with the DEX group; however, this result was not statistically significant $(P=0.076$; Fig. 1d). Furthermore, there was no difference in gastrocnemius muscle weight between the DEX group and the DEX + SE group $(P=0.107$; Fig. $1 \mathrm{a})$. There was no significant difference in the weights of each muscle between the DEX and DEX + GE groups.

\section{Muscle protein content}

The protein content of the TA muscle in the DEX group was lower than in the CTL group (Fig. 2), while that in the DEX + SE group was higher than in the DEX group; however, this difference was not significant $(P=0.068)$. No difference was observed in protein content between the DEX and DEX + GE groups.

\section{Phosphorylation of S6K1 and lipidation of LC3B}

The S6K1 phosphorylation ratio, which is calculated by dividing $\beta+\gamma$ forms by total forms, in gastrocnemius muscle was markedly lower in the DEX group than in the CTL group (Fig. 3). Although S6K1 phosphorylation in the DEX + SE group was marginally higher than in the DEX group, the difference was not statistically significant $(P=0.122)$. There was no difference in S6K1 phosphorylation level between the DEX and DEX + GE groups.
Both LC3B-I and LC3B-II levels in gastrocnemius muscle were significantly increased by dexamethasone treatment (Fig. 4). Although LC3B-II protein levels in the $\mathrm{DEX}+\mathrm{SE}$ and DEX + GE groups were slightly lower than in the DEX group, the differences were not significant $(P=0.163,0.162$ respectively).

\section{mRNA expression}

In the TA muscle, atrogin-1 (Fig. 5a) and MuRF1 (Fig. 5b) mRNA were significantly increased, while IGF-1 mRNA (Fig. 5c) was significantly decreased following dexamethasone treatment. Atrogin-1 (Fig. 5a) and MuRF1 (Fig. 5b) mRNA expression in the DEX + SE group was significantly lower than in the DEX group; however, there was no difference between the DEX + GE and DEX groups. No difference in IGF-1 mRNA expression was detected between the DEX group and either of the extract supplemented groups (Fig. 5c).

\section{Thiobarbituric acid reactive substances}

Muscle oxidative stress was assessed by measuring thiobarbituric acid reactive substances (TBARS). There were no significant differences in TBARS levels among all groups (CTL: $1.92 \pm 0.43$, DEX: $2.13 \pm 0.37$, DEX + SE: $2.30 \pm 0.48, \mathrm{DEX}+\mathrm{GE}: 1.21 \pm 0.09 \mu \mathrm{mol} \mathrm{MDA} / \mathrm{g}$ protein).

\section{Discussion}

In this study, we examined the inhibitory effects of polyphenol-rich fruit extracts on skeletal muscle atrophy. The supplementation of shiikuwasha extract significantly attenuated dexamethasone-induced weight loss in TA muscle $(P=0.040)$ and tended to attenuate weight loss in EDL muscle $(P=0.076)$. To take into account the water and fat contents in muscle weight, we measured the protein content of muscle. The dexamethasone-induced decrease in TA protein content tended to be attenuated 

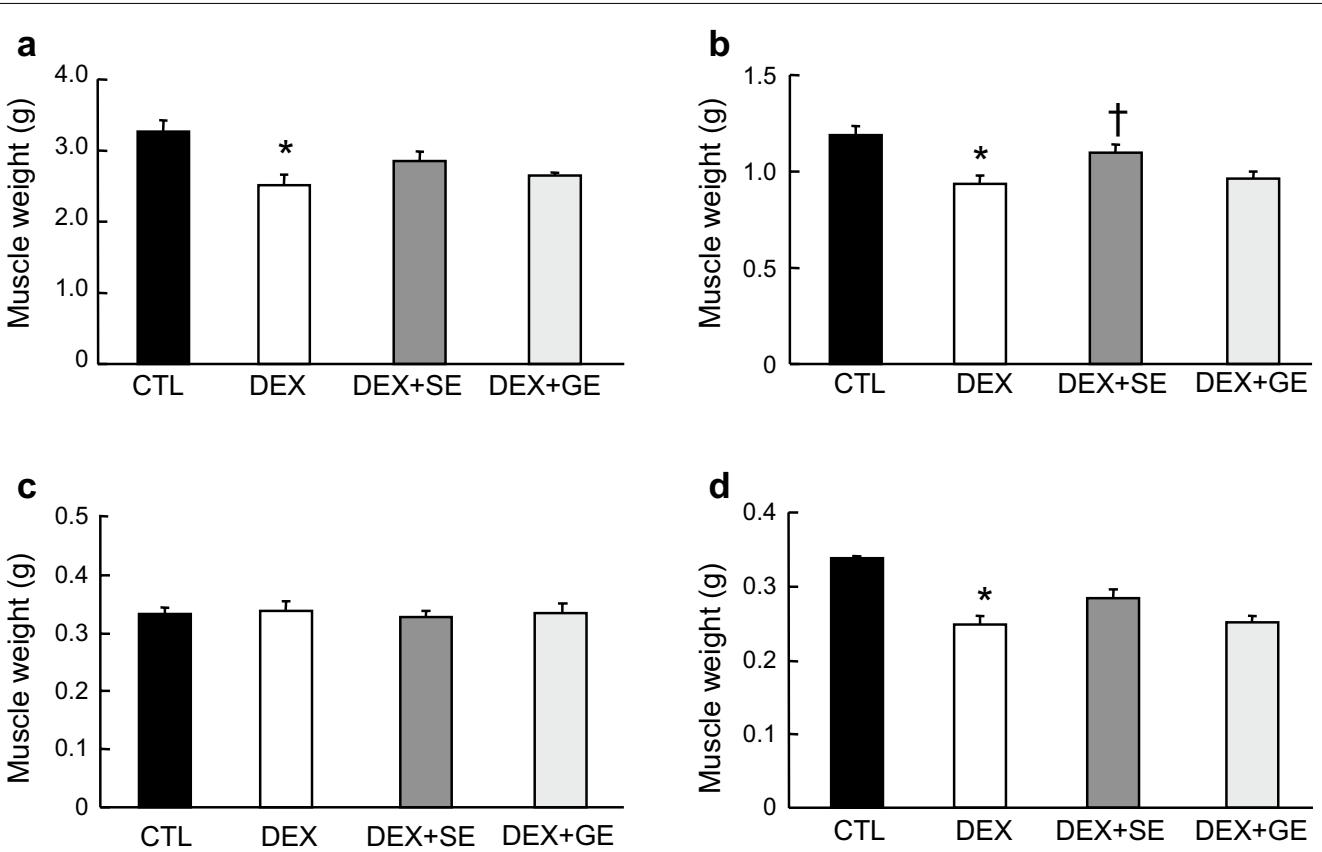

Fig. 1 Effect of shiikuwasha extract or grape extract supplementation on dexamethasone-induced changes in hind-limb muscle weight. Rats were fed an extract-supplemented diet for 19 days. During the last 5 days of feeding, the DEX, DEX + SE and DEX + GE groups were injected with dexamethasone, while the CTL group was injected with an equal volume of saline. After 5 days of dexamethasone treatment, hind-limb muscles were collected and weighed. a Gastrocnemius muscle, b tibialis anterior muscle, c soleus muscle, $\mathbf{d}$ extensor digitorum longus muscle. CTL control, DEX dexamethasone, $D E X+S E$ dexamethasone + shiikuwasha extract, $D E X+G E$ dexamethasone + grape extract. Values are mean $\pm S E M(n=5$ or 6$)$. ${ }^{*} P<0.05 C T L$ versus DEX (student's t-test), ${ }^{\dagger} P<0.05$ versus DEX (Dunnett's test)

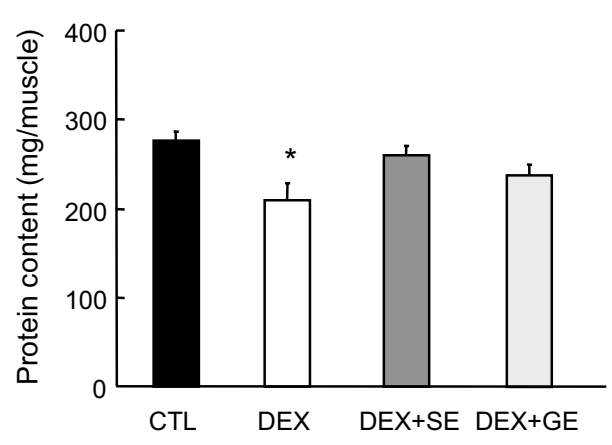

Fig. 2 Effect of shiikuwasha extract or grape extract supplementation on dexamethasone-induced changes in protein content. Protein content of TA muscles was determined using the DC protein assay. $C T L$ control, DEX dexamethasone, DEX + SE dexamethasone + shiikuwasha extract, $D E X+G E$ dexamethasone + grape extract. Values are mean \pm SEM ( $n=5$ or 6$)$. ${ }^{*} P<0.05 C T L$ versus DEX (student's t-test)

by the diet supplemented with shiikuwasha extract $(P=0.068)$. Grape extract, on the other hand, did not have any noteworthy effect on muscle atrophy.

The catabolic action of glucocorticoids on skeletal muscle is thought to result from the activation of proteolytic
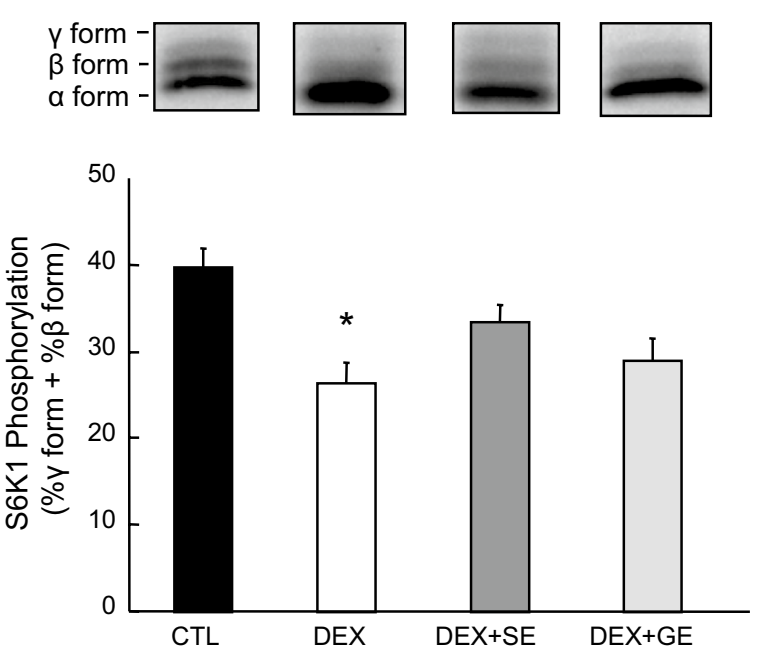

Fig. 3 Effect of shiikuwasha extract or grape extract supplementation on dexamethasone-induced changes in S6K1 phosphorylation. Phosphorylation of $56 \mathrm{~K} 1$ in gastrocnemius muscle was expressed as the amount of S6K1 in the $\beta$ and $\gamma$ forms as percentage of total S6K1. $C T L$ control, DEX dexamethasone, DEX + SE dexamethasone + shiikuwasha extract, $D E X+G E$ dexamethasone + grape extract. Values are mean $\pm \operatorname{SEM}(n=5$ or 6$) .{ }^{*} P<0.05 C T L$ versus DEX (student's t-test) 

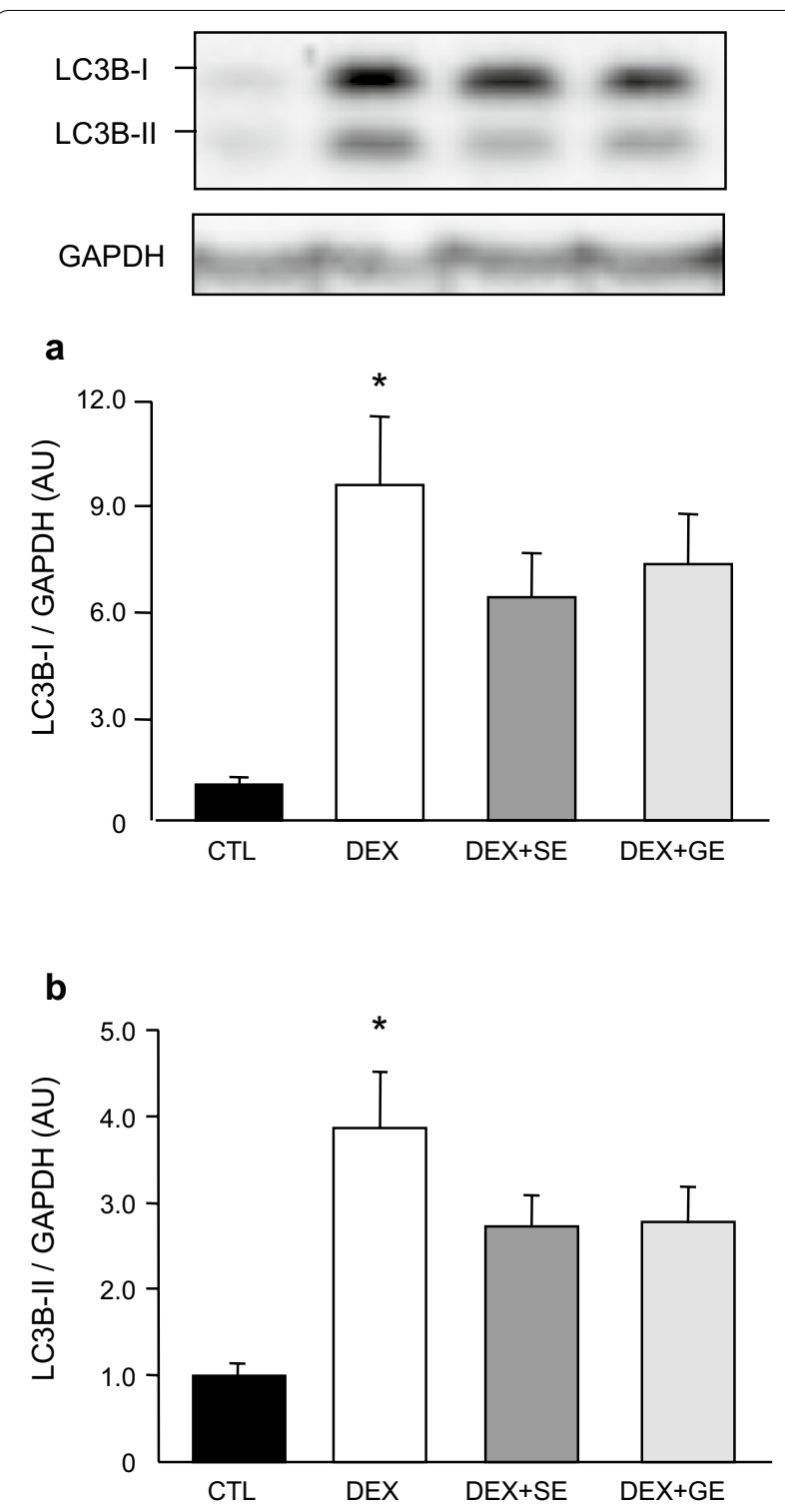

Fig. 4 Effect of shiikuwasha extract or grape extract supplementation on dexamethasone-induced changes in LC3B-I and LC3B-II. Both LC3B-I and LC3B-II protein levels in gastrocnemius muscle were normalized to GAPDH. a LC3B-I normalized to GAPDH, b LC3B-II normalized to GAPDH. CTL control, DEX dexamethasone, DEX + SE dexamethasone + shiikuwasha extract, $D E X+G E$ dexamethasone + grape extract. Values are mean \pm SEM $(n=5$ or 6$)$. ${ }^{*} P<0.05$ CTL versus DEX (student's t-test)

pathways, in particular the ubiquitin-proteasome system and the autophagy-lysosomal system. It has been reported that glucocorticoids activate FOXO and KLF15 expression via the glucocorticoid receptor (GR) (Shimizu et al. 2011). These proteins promote gene expression of atrophy-stimulating genes such as atrogin-1 and MuRF1. In the present study, the supplementation of shiikuwasha extract reduced dexamethasone-induced increases in atrogin-1 and MuRF1 mRNA expression. Although we did not examine the effects of shiikuwasha extract on FOXO and KLF15, it is possible that shiikuwasha extract also inhibits the expression and/or activation of these factors. Penna et al. reported that dexamethasone treatment elevated LC3B-I and LC3B-II protein levels and reduced P62/SQSTM1 levels in young mice (Penna et al. 2013). In this study, LC3B-I and LC3B-II were increased similarly by dexamethasone treatment. It has been suggested that autophagy is activated by dexamethasone administration. However, the supplementation of shiikuwasha extract did not reduce LCB3-I and LC3B-II protein levels. These results indicate that shiikuwasha extract may inhibit the elevation of the ubiquitin-proteasome system but does not affect the autophagy-lysosomal system in glucocorticoid-induced muscle atrophy.

Glucocorticoids also inhibit muscle protein synthesis. Phosphorylation of S6K1 and eIF4E-binding protein 1 (4E-BP1) are inhibited by glucocorticoids via blunting of anabolic stimuli such as insulin, insulin-like growth factor-I (IGF-I), and amino acids (leucine) (Shah et al. 2000a, b; Liu et al. 2001, 2004). In the present study, S6K1 phosphorylation was significantly reduced by dexamethasone treatment. The supplementation of shiikuwasha extract slightly attenuated the inhibition of S6K1 phosphorylation, while the supplementation of grape extract had no effect. In addition, IGF-1 mRNA expression was significantly reduced by dexamethasone treatment. Neither extract had any effect on IGF-1 mRNA expression. There are a few reports concerning the influence of nobiletin on protein synthesis. Lee et al. reported that nobiletin upregulates Akt phosphorylation in diabetic ob/ ob mice (Lee et al. 2010). This result suggests that polymethoxylated flavones improve protein synthesis under certain catabolic conditions, such as diabetes mellitus. Similarly, shiikuwasha extract may also have a positive effect on mTOR signaling and protein synthesis.

Glucocorticoid excess induces acute insulin resistance (Pagano et al. 1983) and increases oxidative stress (Iuchi et al. 2003). Antioxidant vitamins $C$ and $E$ have been reported to improve glucocorticoid-induced glucose intolerance (Williams et al. 2012). Furthermore, vitamin E attenuates oxidative stress and skeletal muscle atrophy induced by glucocorticoids (Ohtsuka et al. 1998). One possible mechanism of these beneficial effects of vitamins $E$ and $C$ could be due to a reduction in glucocorticoid-induced oxidative stress. In this study, serum insulin was increased by dexamethasone, however TBARS in the EDL muscle was not increased. The reason why an increase in the TBARS level was not observed is probably due to the elevation of TBARS with increasing age. Furthermore, dietary supplementation with either shiikuwasha or grape extract did not have an effect on the 

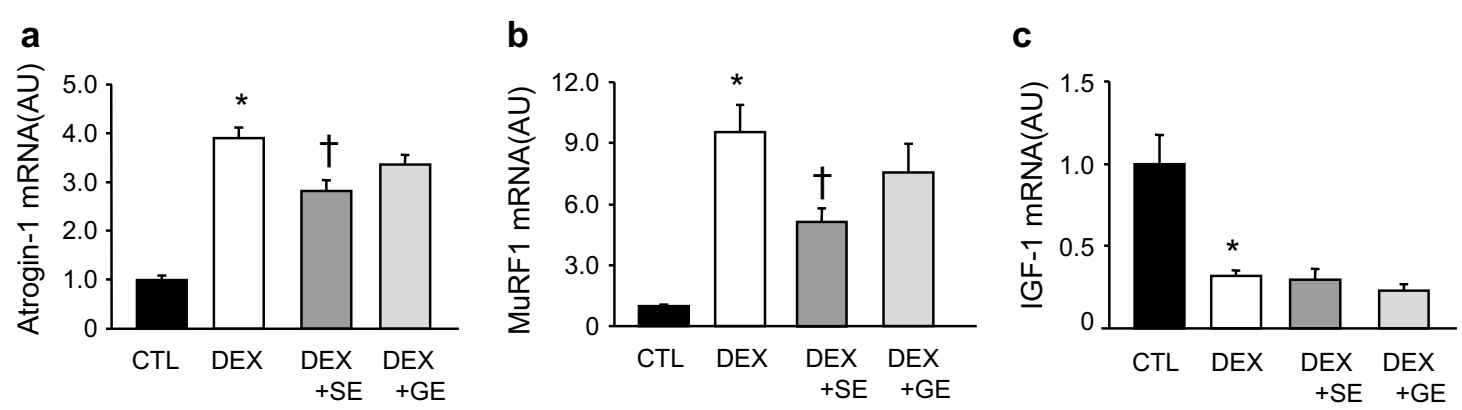

Fig. 5 Effect of shiikuwasha extract or grape extract supplementation on dexamethasone-induced changes in mRNA expression. The mRNA was extracted from tibialis anterior muscles and measured using RT-PCR. The mRNA expression was normalized to GAPDH. a Atrogin-1 mRNA expression, b MURF1 mRNA expression, c IGF-1 mRNA expression. CTL control, DEX dexamethasone, DEX + SE dexamethasone + shiikuwasha extract, $D E X+G E$ dexamethasone + grape extract. Values are mean \pm SEM $(n=5$ or 6$) .{ }^{*} P<0.05 C T L$ versus DEX (student's t-test), ${ }^{\dagger} P<0.05$ versus DEX (Dunnett's test)

levels of TBARS and serum insulin. Decreased oxidative stress and increased endogenous anti-oxidative enzymes associated with the intake of polyphenols are suggested as plausible mechanisms by which polyphenols attenuate skeletal muscle atrophy. In particular, it has been indicated that resveratrol, via a pathway that involves the activation of SIRT1 and the up-regulation of antioxidant defense mechanisms (Ungvari et al. 2009), attenuates oxidative stress in aged skeletal muscle (Jackson et al. 2011). While an effect of dietary supplementation with shiikuwasha on TBARS levels was not observed in the present study, the possibility that shiikuwasha extract has an inhibitory effect on oxidative stress, and that this effect is involved in the attenuation of skeletal muscle atrophy, cannot be discounted. This contention is supported by the fact that shiikuwasha extract contains nobiletin, which has antioxidative activity (Lu et al. 2010), and by the observation that an increase in oxidative stress in response to dexamethasone was not observed in the present study. Many studies have provided evidence of the inhibitory effects of resveratrol on muscle atrophy in various animal models, such as disuse (Jackson et al. 2010), diabetes (Chen et al. 2011), and cancer cachexia (Shadfar et al. 2011). In addition, resveratrol inhibited dexamethasone-induced protein degradation in L6 myotubes (Alamdari et al. 2012); however, a grape extract containing resveratrol had no effect on skeletal muscle atrophy in the present study. Shadfar et al. suggested that a resveratrol dose of at least $200 \mathrm{mg} / \mathrm{kg} /$ day might be necessary to prevent cancer cachexia-induced muscle atrophy (Shadfar et al. 2011). The dose of grape extract used in this study may be insufficient to prevent glucocorticoidinduced muscle atrophy.

Neither the inhibitory effect of shiikuwasha extract nor that of polymethoxylated flavones in shiikuwasha fruit on muscle atrophy has been reported. In addition, there are few reports on the effects of this extract or polymethoxylated flavones on either protein synthesis or degradation. Further studies are needed to elucidate the mechanisms of the inhibitory effects of shiikuwasha extract on muscle atrophy. It is also necessary to determine the effect of shiikuwasha extract on muscle atrophy resulting from other causes such as disuse.

\section{Conclusions}

We found that shiikuwasha extract attenuated dexamethasone-induced skeletal muscle atrophy in aged rats. Although the exact mechanism has not been fully defined, shiikuwasha extract may partially inhibit the activation of the ubiquitin-proteasome system and may consequently attenuate skeletal muscle atrophy induced by dexamethasone in aged rats. Our findings indicate that shiikuwasha extract could be useful for attenuating muscle atrophy associated with increases in circulating glucocorticoid levels, such as in sepsis, cachexia, and starvation.

\section{Authors' contributions}

YS, KO and TO carried out the experiments. YS, HN and FY conceived of the study, participated in its design and wrote the paper. HI, KN and YT contributed to the planning of experiments and reviewed/edited the manuscript. All authors read and approved the final manuscript.

\section{Author details}

${ }^{1}$ Nutrition Research Department, Nutritional Science Institute, Morinaga Milk Industry Co., Ltd., 1-83, 5-Chome, Higashihara, Zama, Kanagawa 252-8583, Japan. ${ }^{2}$ Department of Agrobiology and Bioresources, Faculty of Agriculture, Utsunomiya University, 350, Mine-machi, Utsunomiya, Tochigi 321-8505, Japan.

\section{Competing interests}

Y. Sakata, T. Okamoto, K. Oshio, H. Nakamura, H. Iwamoto, K. Namba and Y. Takeda are employees of Morinaga Milk Industry Co., LTD. F. Yoshizawa has no competing interests to declare. The Morinaga Milk Industry Co., LTD. is applying for a patent relating to the content of this manuscript.

Received: 7 August 2015 Accepted: 26 May 2016

Published online: 21 June 2016 


\section{References}

Alamdari N, Aversa Z, Castillero E, Gurav A, Petkova V, Tizio S, Hasselgren PO (2012) Resveratrol prevents dexamethasone-induced expression of the muscle atrophy-related ubiquitin ligases atrogin-1 and MuRF1 in cultured myotubes through a SIRT1-dependent mechanism. Biochem Biophys Res Commun 417:528-533

Auclair D, Garrel DR, Chaouki Zerouala A, Ferland LH (1997) Activation of the ubiquitin pathway in rat skeletal muscle by catabolic doses of glucocorticoids. Am J Physiol Cell Physiol 272:C1007-C1016

Chen KH, Cheng ML, Jing YH, Chiu DT, Shiao MS, Chen JK (2011) Resveratrol ameliorates metabolic disorders and muscle wasting in streptozotocininduced diabetic rats. Am J Physiol Endocrinol Metab 301:E853-E863

Dardevet D, Sornet C, Savary I, Debras E, Patureau-Mirand P, Grizard J (1998) Glucocorticoid effects on insulin- and IGF-I-regulated muscle protein metabolism during aging. J Endocrinol 156:83-89

Dekhuijzen PN, Gayan-Ramirez G, Bisschop A, De Bock V, Dom R, Decramer M (1995) Corticosteroid treatment and nutritional deprivation cause a different pattern of atrophy in rat diaphragm. J Appl Physiol 78:629-637

Fischer D, Sun X, Gang G, Pritts T, Hasselgren PO (2000) The gene expression of ubiquitin ligase E3a is upregulated in skeletal muscle during sepsis in rats-potential role of glucocorticoids. Biochem Biophys Res Commun 267:504-508

Fitts RH, Romatowski JG, Peters JR, Paddon-Jones D, Wolfe RR, Ferrando AA (2007) The deleterious effects of bed rest on human skeletal muscle fibers are exacerbated by hypercortisolemia and ameliorated by dietary supplementation. Am J Physiol Cell Physiol 293:C313-C320

Gayan-Ramirez G, Vanderhoydonc F, Verhoeven G, Decramer M (1999) Acute treatment with corticosteroids decreases IGF-1 and IGF-2 expression in the rat diaphragm and gastrocnemius. Am J Respir Crit Care Med 159:283-289

Howitz KT, Bitterman KJ, Cohen HY, Lamming DW, Lavu S, Wood JG, Zipkin RE, Chung P, Kisielewski A, Zhang LL, Scherer B, Sinclair DA (2003) Small molecule activators of sirtuins extend Saccharomyces cerevisiae lifespan. Nature 425:191-196

luchi T, Akaike M, Mitsui T, Ohshima Y, Shintani Y, Azuma H, Matsumoto T (2003) Glucocorticoid excess induces superoxide production in vascular endothelial cells and elicits vascular endothelial dysfunction. Circ Res 92:81-87

Jackson JR, Ryan MJ, Hao Y, Alway SE (2010) Mediation of endogenous antioxidant enzymes and apoptotic signaling by resveratrol following muscle disuse in the gastrocnemius muscles of young and old rats. Am J Physiol Regul Integr Comp Physiol 299:1572-1581

Jackson JR, Ryan MJ, Alway SE (2011) Long-term supplementation with resveratrol alleviates oxidative stress but does not attenuate sarcopenia in aged mice. J Gerontol A Biol Sci Med Sci 66:751-764

Kimball SR, Horetsky RL, Jefferson LS (1998) Signal transduction pathways involved in the regulation of protein synthesis by insulin in L6 myoblasts. Am J Physiol 274:C221-C228

Lai CS, Li S, Chai CY, Lo CY, Dushenkov S, Ho CT, Pan MH, Wang YJ (2008) Anti-inflammatory and antitumor promotional effects of a novel urinary metabolite, 3',4'-didemethylnobiletin, derived from nobiletin. Carcinogenesis 29:2415-2424

Landi F, Liperoti R, Russo A, Giovannini S, Tosato M, Capoluongo E, Bernabei R, Onder $G$ (2012) Sarcopenia as a risk factor for falls in elderly individuals: results from the ilSIRENTE study. Clin Nutr 31:652-658

Lee YS, Cha BY, Saito K, Yamakawa H, Choi SS, Yamaguchi K, Yonezawa T, Teruya T, Nagai K, Woo JT (2010) Nobiletin improves hyperglycemia and insulin resistance in obese diabetic ob/ob mice. Biochem Pharmacol 79:1674-1683

Liu Z, Jahn LA, Long W, Fryburg DA, Wei L, Barrett EJ (2001) Branched chain amino acids activate messenger ribonucleic acid translation regulatory proteins in human skeletal muscle, and glucocorticoids blunt this action. J Clin Endocrinol Metab 86:2136-2143

Liu Z, Li G, Kimball SR, Jahn LA, Barrett EJ (2004) Glucocorticoids modulate amino acid-induced translation initiation in human skeletal muscle. Am J Physiol Endocrinol Metab 287:E275-E281

Lu YH, Su MY, Huang HY, Lin-Li, Yuan CG (2010) Protective effects of the citrus flavanones to PC12 cells against cytotoxicity induced by hydrogen peroxide. Neurosci Lett 484:6-11
Minet-Quinard R, Moinard C, Walrand S, Villié F, Normand B, Vasson MP, Chopineau J, Cynober L (2000) Induction of a catabolic state in rats by dexamethasone: dose or time dependency? JPEN J Parenter Enteral Nutr 24:30-36

Momken I, Stevens L, Bergouignan A, Desplanches D, Rudwill F, Chery I, Zahariev A, Zahn S, Stein TP, Sebedio JL, Pujos-Guillot E, Falempin M, Simon C, Coxam V, Andrianjafiniony T, Gauquelin-Koch G, Picquet F, Blanc S (2011) Resveratrol prevents the wasting disorders of mechanical unloading by acting as a physical exercise mimetic in the rat. FASEB J 25:3646-3660

Mukai R, Horikawa H, Fujikura Y, Kawamura T, Nemoto H, Nikawa T, Terao J (2012) Prevention of disuse muscle atrophy by dietary ingestion of 8-prenylnaringenin in denervated mice. PLoS One 7:e45048

Nogata Y, Sakamoto K, Shiratsuchi H, Ishii T, Yano M, Ohta H (2006) Flavonoid composition of fruit tissues of citrus species. Biosci Biotechnol Biochem 70:178-192

Ohkawa H, Ohishi N, Yagi K (1979) Assay for lipid peroxides in animal tissues by thiobarbituric acid reaction. Anal Biochem 95:351-358

Ohtsuka A, Kojima H, Ohtani T, Hayashi K (1998) Vitamin E reduces glucocorticoid-induced oxidative stress in rat skeletal muscle. J Nutr Sci Vitaminol (Tokyo) 44:779-786

Pagano G, Cavallo-Perin P, Cassader M, Bruno A, Ozzello A, Masciola P, Dall'omo AM, Imbimbo B (1983) An in vivo and in vitro study of the mechanism of prednisone-induced insulin resistance in healthy subjects. J Clin Invest 72:1814-1820

Penna F, Costamagna D, Pin F, Camperi A, Fanzani A, Chiarpotto EM, Cavallini G, Bonelli G, Baccino FM, Costelli P (2013) Autophagic degradation contributes to muscle wasting in cancer cachexia. Am J Pathol 182:1367-1378

Rieu I, Sornet C, Grizard J, Dardevet D (2004) Glucocorticoid excess induces a prolonged leucine resistance on muscle protein synthesis in old rats. Exp Gerontol 39:1315-132

Ruzzin J, Wagman AS, Jensen J (2005) Glucocorticoid-induced insulin resistance in skeletal muscles: defects in insulin signaling and the effects of a selective glycogen synthase kinase-3 inhibitor. Diabetologia 48:2119-2130

Sandri M (2013) Protein breakdown in muscle wasting: role of autophagy-lysosome and ubiquitin-proteasome. Int J Biochem Cell Biol 45:2121-2129

Schakman O, Gilson H, Thissen JP (2008) Mechanisms of glucocorticoidinduced myopathy. J Endocrinol 197:1-10

Shadfar S, Couch ME, McKinney KA, Weinstein LJ, Yin X, Rodríguez JE, Guttridge DC, Willis M (2011) Oral resveratrol therapy inhibits cancer-induced skeletal muscle and cardiac atrophy in vivo. Nutr Cancer 63:749-762

Shah OJ, Kimball SR, Jefferson LS (2000a) Acute attenuation of translation initiation and protein synthesis by glucocorticoids in skeletal muscle. Am J Physiol Endocrinol Metab 278:E76-E82

Shah OJ, Kimball SR, Jefferson LS (2000b) Among translational effectors, p70S6 $\mathrm{k}$ is uniquely sensitive to inhibition by glucocorticoids. Biochem J 347:389-397

Shimizu N, Yoshikawa N, Ito N, Maruyama T, Suzuki Y, Takeda S, Nakae J, Tagata Y, Nishitani S, Takehana K, Sano M, Fukuda K, Suematsu M, Morimoto C, Tanaka H (2011) Crosstalk between glucocorticoid receptor and nutritional sensor mTOR in skeletal muscle. Cell Metab 13:170-182

Siemann EH, Creasy LL (1992) Concentration of the phytoalexin resveratrol in wine. Am J Enol Vitic 43:49-52

Subbaramaiah K, Chung WJ, Michaluart P, Telang N, Tanabe T, Inoue H, Jang M, Pezzuto JM, Dannenberg AJ (1998) Resveratrol inhibits cyclooxygenase-2 transcription and activity in phorbol ester-treated human mammary epithelial cells. J Biol Chem 273:21875-21882

Ungvari Z, Labinskyy N, Mukhopadhyay P, Pinto JT, Bagi Z, Ballabh P, Zhang C, Pacher P, Csiszar A (2009) Resveratrol attenuates mitochondrial oxidative stress in coronary arterial endothelial cells. Am J Physiol Heart Circ Physiol 297:H1876-H1881

Williams DB, Wan Z, Frier BC, Bell RC, Field CJ (2012) Dietary supplementation with vitamin $\mathrm{E}$ and $\mathrm{C}$ attenuates dexamethasone-induced glucose intolerance in rats. Am J Physiol Regul Integr Comp Physiol 302:R49-R58

Yoshizawa F, Sekizawa H, Hirayama S, Hatakeyama A, Nagasawa T, Sugahara K (2001) Time course of leucine-induced 4E-BP1 and S6K1 phosphorylation in the liver and skeletal muscle of rats. J Nutr Sci Vitaminol 47:311-315 